\author{
Alina-Andreea \\ Dragoescu Urlica ${ }^{1}$ \\ Laura-Ioana \\ Coroama-Dorneanu \\ Lulzime Kamberi \\ Natalia Malenko \\ Article info: \\ Received 10.04.2019 \\ Accepted 21.06.2019 \\ UDC -159.953 .5$ \\ DOI - 10.24874/IJQR13.03-16
}

\section{SUSTAINABLE LEARNING AND MATERIAL DEVELPMENT IN ESP - ENGLISH FOR THE LIFE SCIENCES}

Abstract: The paper presents the follow-up of a case study investigation with students of ESP (English for Specific Purposes) on a tertiary level (1st and 4th year students), consisting of collaborative learner-teacher activities, including concept mapping and content-based learning. The results of our project in progress are considered for an optimal adaptation of an ESP textbook which is intended for students in several areas related to the Life Sciences (Agriculture, Biotechnologies, Biology, Genetic Engineering, Horticulture, etc.). The framework of the course support we propose, as well as our methodology and tool kit are provided by ecolinguistics and the aim is achieving ecological learning and meaningful communication in the language class and beyond. The object of this exploratory study is to highlight the potential of collaborative learning environments, to enable students to employ conceptual mapping and find relations between significant concepts in the Life Sciences. The feedback was collected from ESP learners as materials were collaboratively selected and designed together with students, based on the construction of conceptual maps. The question raised in our preliminary study draws on a review of the literature pertinent to meaningful conceptual learning. Some of the key concepts addressed in the ecologically-designed English courses are analysed, focusing on feedback from the students and constantly adapting our findings to better serve their needs.

Keywords: ESP (English for Specific Purposes), meaningful learning, quality, conceptual mapping, Content-based instruction.

\section{Introduction}

The qualitative investigation we propose aims at exploring the deep implications of acquiring English for Specific Purposes (ESP) based on the ecolinguistic approach, within collaborative environments which encourage a higher-level integration of knowledge (Dragoescu Urlica \& Stefanović, 2018). Involving students in creating such an environment together and helping them become skilled at concept mapping leads to the construction of a more holistic value system, which we mean to include in our language and communication curriculum. This proposed framework, drawing on Content-based instruction, conceptual mapping, and collaborative course design displays educational benefits which far outreach the restrictive technicalities of

${ }^{1}$ Corresponding author: Alina-Andreea Dragoescu Urlica Email: andreeadragoescu@yahoo.com 
language structure acquisition (Dragoescu Urlica et al., 2018).

\section{Methodology}

\subsection{Aims and methods}

The aim of this study is to present the contributions drawn from the preliminary investigation we deployed (Dragoescu Urlica et al., 2019) to explore the utility of conceptual map construction for eliciting meaningful thinking skills. Together with our undergraduate students of ESP in the area of Life Sciences, we looked for ways in which we might apply concept maps to help them better grasp meaning, draw connections between ideas, and fully deploy their educational potential.

\subsection{Settings and Participants}

The participants in our qualitative exploratory workshops were $1^{\text {st }}$ and $4^{\text {th }}$-year students from Romania, Poland, and North Macedonia, aged between 18 and 22, enrolled in various faculties of Life Sciences (Agriculture, Biotechnologies, Biology, Genetic Engineering, Horticulture, etc.) and in Language and Communication courses. Findings indicate that our proposed system of combining concept mapping with contentbased learning in collaborative environments has the potential to enhance highly relevant soft skills such as critical and creative thinking, as well as meaningful learning to elaborate projects and find patterns of connectivity.

Our target is to promote respect for others and learn to take responsibility for one's own learning and for that of peers to reach optimized outcomes in research projects which involve collaborative and team work (Matthews et al., 2004).

Besides class observation during workflow, we also employed free surveys to elicit perceptions from learners regarding the ESP environment and the utility of concept mapping in rendering learning relevant to their needs (Ferreira \& Lantolf, 2008).

The course of English for the Life Sciences is intended to contribute to the development of quality education and to encourage ecological stances towards the environment, in professional, as well as personal and educational spaces.

\section{Results and Discussion}

\subsection{Synchronizing Conceptual mapping with Content-based strategies in ESP}

The creation of new materials for ESP courses combines content-based strategies with principles revolving around holistic values and meaning-making abilities we wish to develop. From a "quality of experience" perspective, students who meaningfully participate in their own learning experience are able to achieve a more internalized acquisition of language as well as knowledge, which impacts their education on a level beyond formal language training. Our strategic endeavour emphasizes meaning and conceptual content quality above other formal aspects which have traditionally received precedence in language classes.

In addition, achieving meaningful pedagogy entails taking into consideration the "local exigencies and lived experiences" in relation to the given context of learning (Kumaravadivelu, 2006). Despite the students' experiential limits in acquiring language structures, our observations confirm that adult learners are generally well equipped to comprehend higher conceptual complexity and they are able to make use of conceptual learning abilities, as suggested by Cozma (2015). They are also more cooperative learners, as a result of "their seeing the point of the various instructional situations in which they are involved" (Cozma, 2015). Therefore, we must strive to help learners see the point in learning, which 
is to gain a more coherent understanding of their target domain of primary interest.

A growing body of research in the field of Language learning highlights the importance of content-based learning and concept mapping in the area of languages as well as life sciences (Novak, 1990). Work in this area points to the influence of concept maps on the quality of learning outcomes (de Cássia Veiga Marriott, 2010; Lupion Torres, 2010; O'Donnell et al., 2002). Teaching with a view to enable understanding implies making contents meaningful and using innovative tools such as concept mapping or semantic networking (Mintzes et al., 2000; Fisher, 2000). Conceptual maps can readily be constructed in domains of knowledge related to the Life sciences and cross-links may be sought to make various connections between different concepts across the map and also clarify how multiple domains of life are related to one another (Cabaní \& Bosch, 2010). Therefore, concept mapping is seen as a good tool to organize and better articulate learning, which serves to clarify relations between concepts, to assimilate information and ultimately to find solutions to problems (Novak \& Gowin, 1984).

Thereby, concept mapping facilitates meaningful learning as it connects ideas and provides structure which is "built up piece by piece with small units of interacting concept and propositional frameworks" (Novak, 2001). Students work collectively to construct concept maps by finding ways of relating concepts they have already learned. These learning tools work especially well in collaborative settings of EFL and this association may help students and teachers adapt to rapidly changing needs and improve performance (Preszler, 2004). Teaching with a view to enable understanding implies making contents meaningful and using innovative tools such as concept mapping or semantic networking (Mintzes et al., 2000; Fisher, 2000). What is more, meaningful learning has the potential to confer more empowerment on learners, who become responsible for organizing their own knowledge to gain higher correlational understanding (Novak, 2002). Links between conceptual focal points (usually Nouns/Noun phrases) are represented with arrows, on which learners add suitable "linking words". Any combination of two concepts connected through such a link represents a "proposition" (Novak, 1990). Then, peer feedback verifies whether cross-links are meaningfully related and propositions are flexibly redistributed, as learners store maps which are naturally embedded within their knowledge system.

Possibilities of rewordings by making various connections between different focal points give way to a multiplicity of dynamic patterns, which offers learners a greater freedom of expression, building connectionmaking skills and allowing them to make deductive causal-effect judgements more clearly. Results indicate that the use of collaborative conceptual mapping encourages free dialogue on conceptual and deductive aspects, regardless of grammatical limitations.

In addition, too much emphasis on memorising specialty jargon reduces comprehension and the students'immediate need of communicating and interacting in the language to be acquired. This actually leads to "a loss of general communication range" (Wandersee, 2002). In this respect, Wandersee (2002) discusses the "terminology paradox" - that acquiring specialized vocabulary in a given field ensures more precision in a future professional occasion which may not occur. What is more, even without having acquired vocabularies, when we begin to learn how to speak, we first focus on meaning rather than on language; seemingly, "meaning-making comes first" (Wandersee, 2002).

Consequently, the process of meaningmaking, profound understanding, and coconstruction of knowledge structured in semantic schemes is of far greater relevance. The structure of complex mapped representations becomes "a semantic 
coordinating element", which enhances understanding by posing constraints between terms (Fisher et al., 2002). In Mapping Biology Knowledge, Fisher et al. (2002) make a particular case in point by highlighting two key topics: promoting meaningful learning and knowledge mapping as a strategy for achieving this goal. The tool kit they propose includes, besides concept maps, semantic networks or clusters, webs, and conceptual graphs, which are useful in building both content and cognitive skills synchronously.

\subsection{Key Topics in Ecological Learning - The community as a web of life}

An integrated understanding of ESP learning draws on content-based educational resources which are consistently correlated with the students' primary interests, in line with achieving our basic ecological communication aim. For this purpose, Content-Based Instruction is used as a highly relevant tool to achieve concept development (Fogal, 2015). In turn, concept development helps build a stronger quality of learning (Cabaní \& Bosch, 2010).

Understanding conceptual mapping implies gaining increased awareness of the connections we are able to draw between concepts which may appear isolated when listed in tables, learned from dictionary definitions or from endless texts which may often get students lost or confused. This type of reorganizing knowledge plays exactly on the very concept at the core of connectionmaking processes: understanding the concept of web. One of the key concepts in ecology and any related field within the Life Sciences/Ecolinguistics is the idea that no organism/concept can function in isolation and living forms/communication units are interconnected.

As a result, any disturbances in ecosystems spread and produce further effects in chain, which requires greater responsibility and awareness on our part. The language class becomes a suitable setting to enhance both linguistic competence and collaborative cooperation with members of the community, while raising awareness of environmental issues through language and communication learning materials (Jacobs \& Goatly, 2000).

Understanding the conceptual importance of the taught terminology is of great relevance for tackling the impending environmental crisis we are all contributing to. Among the fundamentals across all domains related to Ecological Engineering, the notion sustainability may be envisioned as a grounding concept for learning in all other areas of science within our university, but also as a foundational frame of mind within the language class itself.

As defined by Asheim (1994), the notion is intimately related to the idea of "quality of life". It is defined as "a requirement of our generation to manage the resource base such that the average quality of life that we ensure ourselves can potentially be shared by all future generations. [...] Development is sustainable if it involves a non-decreasing average quality of life" (Asheim, 1994). Our objective is to model and apply this idea in projects organized by students and thus to extend it to the language class ecosystem which we are striving to make "sustainable".

From an immersive perspective, interaction develops social cognition, coordination with others, as well as intersubjectivity (Suthers, 2006), which also includes a strong participatory component. It is through the learners' coordination dynamics that coordination of meaning is ultimately reached as an effect of co-regulation (Fogel, 1993).

According to Fuchs and De Jaegher (2009), "meanings emerge, become aligned, change and so on through the interpersonal coordinations of movements". In the enactive approach to early intersubjectivity, co-creation of meaning occurs through the mutual incorporation of ideas, which "opens up potential new domains of sense-making", which were not necessarily available to each 
individual previously in isolation (Fuchs \& De Jaegher, 2009).

Optimal communication and ecological interaction have become the focus of a wide array of multidisciplinary theories of embodied cognition and ecologicallyextended models of interactive dynamics. For Maturana (1987), "languaging" represents the capacity to perceive and communicate meaning which is conducive to the construction of "operational coherences" (Maturana 1987). This consensual coordination of meanings enables us to learn and reflect through language use, which we have gradually developed into complex communication systems. Such processes within the eco-linguistic type of class rely on natural synchronization in cooperative workflow and feedback interplay. As students help each other to better process meaning and to interconnect conceptual schemes, they engage in collaborative interplay to achieve a common goal leading to enhanced levels of knowledge and conceptual enrichment.

\section{Conclusion}

The strategic plan for textbook design analysed in the present paper provides experimental validation of the teaching and learning technology we have proposed at the outset. As teaching support developers, we believe that conceptual mapping and the content-based tools presented above benefit undergraduate students of ESP by developing more fluent communication skill sets, better meaning-making and connecting abilities, and other cultural soft skills they are likely to need in life.

There is a greater chance of learning to take place when the students are engaged in meaningful activities which they organize interactively among themselves. In open environments where they have enough space to extend inquiry according to their needs to solve tasks, learners are given a chance to refine their abilities which are in the process of evolving organically and rhizomatically. The students' proficiency in ESP has been assessed on the basis of their superior conceptual competence, which enables them to use language more confidently and to connect phrases with a higher sense of "flow". In conclusion, mere speaker proficiency in the target language is not a sufficient criterion in the training of communicative competences which are so essential to language learning. The formulated hypothesis which has been targeted is thus confirmed in that designing the ESP textbook remains an adaptive process in progress, which we co-construct and permanently revise with colleagues and students.

Acknowledgment: We would like to thank the teachers and students who collaborated in this exploratory research.

\section{References:}

Asheim, G. B. (1994). Sustainability: ethical foundations and economic properties. Policy, Research working paper, WPS 1302. Washington, DC: World Bank.

Cabaní, M. L. P., \& Bosch, J. J. (2010). Using concept mMapping to improve the quality of learning. In M. L. P. Cabaní, and J. Bosch (Eds.), Handbook of research on collaborative learning using concept mapping. Hershey, New York \& London: Information Science Reference.

Cozma, M. (2015). The Challenge of teaching English to adult learners in today's world. Procedia - Social and Behavioral Sciences, 197, 1209-1214. 
de Cássia Veiga Marriott, R. (2010). Collaborative learning and concept mapping for language teaching. In P. Lupion Torres \& R. de Cássia Veiga Marriott (Eds.), Handbook of research on collaborative learning using concept mapping (pp. 13-34). Hershey, New York \& London: Information Science Reference.

Dragoescu Urlica, A. A., \& Stefanović, S. (2018). Ecolinguistic qualities of the optimal English language learning experience. International Journal for Quality Research, 12(2), 537-546.

Dragoescu Urlica, A. A., Coroama-Dorneanu, L. I., Kamberi, L., \& Malenko, N. (2019). ESP for the Life Sciences: designing an English textbook for sustainable learning. International Quality Manual, Proceedings on Engineering Sciences, 1(2), 681-686.

Ferreira, M. M., \& Lantolf, J. P. (2008). A Concept-Based approach to teaching writing through genre analysis. In J. P. Lantolf \& M. E. Poehner (Eds.), Sociocultural Theory and the Teaching of Second Language (pp. 285-320). London: Equinox Publishing.

Fisher, K. M. (2000). SemNet® Semantic Networking. In K. M. Fisher, J. H. Wandersee \& D. E. Moody (Eds.), Mapping biology knowledge (pp. 143-165). Dordrecht: Kluwer Academic Publishers.

Fisher, K., Wandersee, J. H., \& Moody, D. E. (2002). Mapping Biology Knowledge. Springer.

Fogal, G. G. (2015). Pedagogical stylistic and concept-based instruction: An investigation into the development of voice in the academic writing of Japanese university of English (Ph.D. thesis, University of Toronto). Retrieved from: https://tspace.library.utoronto.ca/ bitstream/1807/69299/3/Fogal_Gary_G_201506_PhD_thesis.pdf.

Fogel, A. (1993). Developing through relationships: origins of communication, self and culture. London: Harvester Wheatsheaf.

Fuchs, T., \& De Jaegher, H. 2009. Enactive intersubjectivity: Participatory sense-makingand mutual incorporation. Phenomenology and the Cognitive Sciences, 8, 465-486.

Jacobs G. M., \& Goatly A. (2000). The treatment of ecological issues in ELT coursebooks. ELT Journal, 54, 256-264.

Kumaravadivelu, B. (2006). TESOL methods: changing tracks, challenging trends. TESOL Quarterly, 40(1), 59-81.

Lupion Torres, P. (2010). LOLA: A collaborative learning approach using concept maps. In M. L. P. Cabaní, and J. Bosch (Eds.), Handbook of research on collaborative learning using concept mapping (pp. 1-12). Hershey, New York \& London: Information Science Reference.

Matthews, R. S., Cooper, J. L., \& Hawkes, P. (2004). Building bridges between cooperative and collaborative learning. Change, 27, 35-40.

Maturana, H. (1987). The biological foundations of self-consciousness and the physical domain of existence. In E. Caianiello (Ed.), Physics of Cognitive Processes (pp. 324-379). World Scientific.

Mintzes, J. J., Wandersee, J. H., \& Novak, J. D. (2000). Assessing science understanding: a human constructivist view. San Diego: Academic Press.

Novak, J. D. (1990). Concept Mapping: A Useful Tool for Science Education. Journal of Research in Science Teaching, 27(10), 937-949.

Novak, J. D. (2001). The theory underlying concept maps and how to construct them. Learning Environment Research, 4, 287-324. 
Novak, J. D. (2002). Meaningful learning: The essential factor for conceptual change in limited or appropriate propositional hierarchies (liphs) leading to empowerment of learners. Science Education, 86(4), 548-571.

Novak, J. D., \& Gowin, D. B. (1984). Learning how to learn. Cambridge: Cambridge University Press.

O’Donnell, A., Dansereau, D., \& Hall, R. H. (2002). Knowledge maps as scaffolds for cognitive processing. Educational Psychology Review, 14, 71-86.

Preszler, R. W. (2004). Cooperative concept mapping improves performance in biology. Journal of College Science Teaching, 33, 30-35.

Suthers, D. (2006). Technology affordances for intersubjective meaning making: a research agenda for CSCL. Computer-Supported Collaborative Learning, 1, 315-337.

Wandersee, J. H. (2002). Language, Analogy, and Biology. In K. Fisher, J. H. Wandersee, D. E. Moody (Eds.). Mapping biology knowledge (pp. 95-108). Dordrecht: Kluwer Academic Publishers.

\begin{tabular}{|c|c|c|}
\hline $\begin{array}{l}\text { Alina-Andreea Dragoescu } \\
\text { Urlica } \\
\text { USAMVB "King Michael I of } \\
\text { Romania", Timisoara, } \\
\text { Romania } \\
\text { andreeadragoescu@ yahoo.com }\end{array}$ & $\begin{array}{l}\text { Laura-Ioana Coroama- } \\
\text { Dorneanu } \\
\text { USAMVB “King Michael I of } \\
\text { Romania”, Timisoara, } \\
\text { Romania } \\
\text { lauraioana.coroama@gmail.com }\end{array}$ & $\begin{array}{l}\text { Lulzime Kamberi } \\
\text { University of Tetovo, } \\
\text { Tetovo, Republic of } \\
\text { North Macedonia } \\
\text { 1.kamberi12@gmail.com }\end{array}$ \\
\hline $\begin{array}{l}\text { Natalia Malenko } \\
\text { Lomza State University of } \\
\text { Applied Sciences, } \\
\text { Poland } \\
\text { natalie_malenko@wp.pl }\end{array}$ & & \\
\hline
\end{tabular}




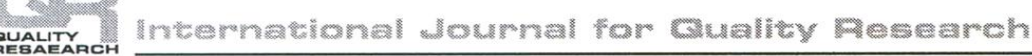

